\title{
Enhancement of hypoxia-induced apoptosis of human breast cancer cells via STAT5b by momilactone B
}

\author{
YOUN-HEE JOUNG ${ }^{1}$, EUN-JOUNG LIM ${ }^{1}$, MI-SUN KIM ${ }^{1}$, SO DUG LIM ${ }^{2}$, SO-YOUNG YOON ${ }^{2}$, \\ YOUNG CHANG LIM ${ }^{2}$, YOUNG BUM YOO ${ }^{3}$, SANG-KYU YE ${ }^{4}$, TAEKYU PARK ${ }^{5}$, \\ ILL-MIN CHUNG $^{6 *}, \mathrm{KI}^{\text {-YEOL BAE }}{ }^{7}$ and YOUNG MOK YANG ${ }^{1}$
}

\begin{abstract}
${ }^{1}$ Department of Pathology, School of Medicine, and Bio-Food and Drug Research Center, Konkuk University, Chungju City 380-701; ${ }^{2}$ Cancer Biology Team of Brain Korea 21 Project, School of Medicine, Konkuk University, Seoul 143-701; ${ }^{3}$ Department of Surgery, School of Medicine, Konkuk University, Seoul 143-701; ${ }^{4}$ Department of Pharmacology, College of Medicine, Seoul National University, Seoul 110-799; ${ }^{5}$ Department of Biotechnology, College of Biomedical and Health Science, Konkuk University, Chungju 380-701; ${ }^{6}$ Department of Applied Life Science, College of Life \& Environment Science, Konkuk University, Seoul 143-701; ${ }^{7}$ Konkuk Natural F\&B Co., Ltd., 701 Industry-Academic

Cooperation Center, Konkuk University, Seoul 143-701, Korea
\end{abstract}

Received April 11, 2008; Accepted June 3, 2008

DOI: 10.3892/ijo_00000030

\begin{abstract}
We have shown previously that hypoxia activates the cyclin D1 promoter via the Jak2/STAT5b pathway in breast cancer cells. Most solid tumors contain hypoxic components and overexpression of cyclin D1. The purpose of the present study was to investigate the molecular mechanism by which momilactone $\mathrm{B}$ exerts its inhibitory effects on breast cancer cells. Momilactone B, extracted from Korean rice hulls, suppressed hypoxia-induced increases in phosphoSTAT5, STAT5b, cyclin D1, and cdk4 protein levels in human breast cancer cells. STAT5b expression was inhibited by siRNA experiments leading to decreased cyclin D1. The effects of momilactone B on cell growth and apoptosisrelated gene expression were investigated in breast cancer cells under hypoxic conditions $\left(2 \% \mathrm{O}_{2}\right)$. Bax and p21 expression was found to be up-regulated, whereas ppRb and bcl-2 were down-regulated in momilactone B-treated cells under hypoxic conditions. However, the p53 protein level did not change. Flow cytometry with Annexin-FITC staining showed that the number of apoptotic cells increased in hypoxic cells
\end{abstract}

Correspondence to: Dr Young Mok Yang, Department of Pathology, School of Medicine, and Bio-Food and Drug Research Center, Konkuk University, Chungju City 380-701, Korea

E-mail: ymyang@kku.ac.kr

${ }^{*}$ Contributed equally

Abbreviations: CDK4, cyclin-dependent kinase 4; DFO, desferrioxamin; EMSA, electrophoretic mobility shift assay; Jak2, Janus kinase 2; STAT5b, signal transducer and activator of transcription $5 \mathrm{~b}$

Key words: hypoxia, momilactone B, STAT5b, apoptosis, human breast cancer cells treated with momilactone B compared with untreated hypoxic cells. Furthermore, caspase activity increased upon treatment with momilactone B under hypoxic conditions. These results indicate that momilactone B inhibits the growth of breast cancer cells, regulates the expression of apoptosisrelated genes, and induces apoptosis through STAT5b and a caspase-3 dependent pathway. We suggest that momilactone B accelerates hypoxia-induced apoptosis of human breast cancer cells through STAT5b, and may represent an effective chemopreventive or therapeutic agent against breast cancer.

\section{Introduction}

Hypoxia, a common effect of solid tumor growth in breast and other cancers, induces a cascade of molecular pathways including angiogenesis, glycolysis, and various cell cycle control proteins, and prolonged hypoxia can induce cell death $(1,2)$. Disordered perfusion and unregulated growth of cancer cells results in a low regional oxygen supply within solid tumors $(3,4)$. The low level of oxygen in human breast and other cancers has been documented with micro-electrodes and is considered a therapeutic problem because it makes solid tumors resistant to radiation and chemotherapy (5). Cells adapt to hypoxic stress via cell-specific protective mechanisms such as cell cycle arrest, reduced energy-dependent protein synthesis, and selective gene induction $(6,7)$.

Signal transducer and activator of transcription 5 (STAT5) regulates growth, differentiation, and survival of mammary and hematopoietic cells. STAT5 may act as a mediator in hypoxia- or DFO (desferrioxamine)-mediated gene expression in mammary epithelial cells (8). Our previous studies showed that STAT5b regulates the transactivation of cyclin D1 and insulin-like growth factor-1 (IGF-1) upon hypoxia stimulation in solid tumor cells $(2,9)$. These results argue that DFO or hypoxia is a critical stimulator for the activation and phosphorylation of STAT proteins in mammary epithelial cells (HC11) and human breast cancer cells (MCF-7) (10). We 
have confirmed that hypoxia or DFO (as a hypoxia inducer) specifically activates STAT5b during hypoxia-stimulated cyclin D1 transactivation in animal and human breast cancer cells (2).

STATs are thought of as having 'yin and yang'-type properties, whereby, depending on the type of cellular stressor, either cell-death or cell-survival pathways are activated $(11,12)$. Dominant-negative STAT5 inhibits the growth of T47D-derived tumors in nude mice via the induction of apoptosis (13). Induction of apoptosis and inhibition of tumor cell proliferation have been used as markers for the evaluation of phytochemical anti-cancer activities (14), and many chemotherapy agents exert their effects by these mechanisms. An imbalance between cell proliferation and apoptosis has been implicated in breast cancer development $(15,16)$.

Cancer chemotherapy has gradually improved with the development of novel antitumor drugs (17). However, many therapeutic anticancer agents exhibit intrinsic and potent cytotoxic activities against normal cells $(18,19)$. Rice is one of the principal cereals in Asia, some countries of Africa, and Latin America (20). Rice hulls are an agricultural byproduct that poses a very serious problem for the global environment (21). Momilactone B was originally isolated from rice hulls as a growth inhibitor involved in seed dormancy and was later found in rice leaves and straw as a phytoalexin $(22,23)$. Recent reports have revealed that momilactone B may represent a novel therapeutic agent to induce cell death in solid tumor cells (17).

We recently reported that hypoxia activates the cyclin D1 promoter via the Jak2/STAT5b pathway in breast cancer cells (2). The purpose of the present study was to investigate the molecular mechanism by which momilactone B exerts its inhibitory effects on breast cancer cells. We predicted that specific blocking of hypoxia-stimulated STAT5b in human breast cancer cells under hypoxic conditions by momilactone B should enhance solid cancer cell apoptosis. Thus, specific inhibition of STAT5b could be another strategy for blocking tumor growth.

In vitro treatment of breast cancer cells under hypoxic conditions with momilactone B induced growth arrest and apoptosis in conjunction with the blockade of the constitutively active Jak-STAT signaling pathway. These results indicate that momilactone B inhibits the growth of breast cancer cells, regulates the expression of apoptosis-related genes, and induces apoptosis through a caspase-3-dependent pathway.

\section{Materials and methods}

Materials. Momilactone B was kindly provided by Dr Il Min Chung (Konkuk University, Korea, Fig. 1). L-15 and RPMI1640 cell growth media were purchased from Gibco-BRL (Grand Island, NY). The cyclin D1 antibody (MS-210-P1) was purchased from Neomarkers (Fremont, CA). PhosphoSTAT5, STAT5b, p21, p53, cdk4, bcl-2, and bax antibodies were purchased from Santa Cruz Biotechnology (Santa Cruz, CA). The phospho-Rb (Ser 795) and cleaved caspase-3 antibodies were from Cell Signaling Technology (CST, Beverly, MA). The pRb antibody was purchased from BD Transduction Laboratories (BD Bioscience, Palo Alto, CA). The FLICA apoptosis detection kit (caspase activity assay)

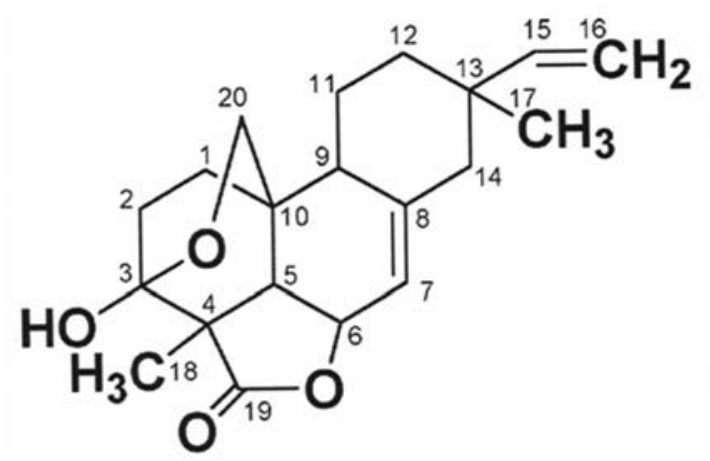

\section{Momilactone B $\left(\mathrm{MW}=330[\mathrm{M}]^{+}\right.$(calc. for $\left.\mathrm{C}_{20} \mathrm{H}_{26} \mathrm{O}_{4}\right)$}

Figure 1. Structure of momilactone B. Rice hulls, from which momilactone $\mathrm{B}$ is extracted, comprise $20 \%$ of the rice grain kernel and, similar to other plant biomass, contains a high percentage of organic substances. It is therefore recognized as a potential source of energy and organic chemicals.

was from Immunochemistry Technologies (Bloomington, $\mathrm{MN})$. The anti-actin antibody, fetal bovine serum (FBS), Hoechst 33258, Annexin V-FITC apoptosis detection kit, and 3-(4,5-dimethylthiazol-2-yl)-2,5-diphenyl tetrazolium bromide (MTT) were obtained from Sigma Chemical Co. (St. Louis, MO). The electrophoretic mobility shift assay (EMSA) kit was purchased from Promega Corp. (Madison, WI). FuGene 6 transfection reagent was from Roche (Basel, Switzerland). The HRP-conjugated donkey anti-rabbit IgG, HRP-conjugated goat anti-mouse IgG, enhanced chemiluminescence (ECL) detection kit, and $\left[\gamma^{-32} \mathrm{P}\right] \mathrm{ATP}$ were purchased from Amersham Pharmacia Biotech (Piscataway, $\mathrm{NJ}$ ). The Coomassie protein assay kit and Restore ${ }^{\mathrm{TM}}$ Western Blot Stripping Buffer were purchased from Pierce (Rockford, IL). The oligonucleotide probes for EMSA analysis were synthesized by Bioneer (Daejeon, Korea).

Cell culture. MCF-7 and T47D human breast cancer cells were cultured in RPMI-1640 medium containing 10\% fetal bovine serum, $2 \mathrm{mM}$ glutamine, and $100 \mathrm{U} / \mathrm{ml}$ penicillin and streptomycin at $37^{\circ} \mathrm{C}$ in $5 \% \mathrm{CO}_{2}$. At the initiation of each experiment, cells were resuspended in the appropriate medium at a density of $2.5 \times 10^{5}$ cells $/ \mathrm{ml}$. For hypoxic conditions, the cells were placed in airtight chambers (NuAire, Plymouth, $\mathrm{MN}$ ) that were flushed with a 5\% carbon dioxide $/ 95 \%$ nitrogen mixture until the oxygen concentration was $2 \%$.

Cytotoxicity determined by MTT assay for cell viability. Cell viability was assayed by measuring blue formazan that was metabolized from 3-(4,5-dimethylthiazol-2-yl)-2,5-diphenyl tetrazolium bromide (MTT) by mitochondrial dehydrogenase, which is active only in live cells. One day before drug application, cells were seeded in 96-well flat-bottomed microtiter plates (3000-5000 cells/well). Cells were incubated for $24 \mathrm{~h}$ with various concentrations of momilactone B under normoxic or hypoxic condition. Twenty microliters of MTT $(5 \mathrm{mg} / \mathrm{ml})$ was added to each well and incubated for $4 \mathrm{~h}$ at $37^{\circ} \mathrm{C}$. The formazan product was dissolved by adding $200 \mu \mathrm{l}$ dimethylsulfoxide (DMSO) to each well, and the plates were read at $550 \mathrm{~nm}$. All measurements were performed in 
triplicate, and each experiment was repeated at least three times.

Detection of apoptosis. For DNA fragmentation analysis, T47D cells were treated with normoxia, hypoxia, or hypoxia plus momilactone B. Treated cells were collected and resuspended in $0.5 \mathrm{ml}$ cold lysis buffer $(20 \mathrm{mM}$ Tris- $\mathrm{HCl}, \mathrm{pH} 7.5$, $10 \mathrm{mM}$ EDTA, $0.5 \%$ Triton X-100) for $30 \mathrm{~min}$. Supernatants were treated with proteinase $\mathrm{K}(20 \mu \mathrm{g} / \mathrm{ml})$ and RNase A $(10 \mu \mathrm{g} / \mathrm{ml})$, and DNA was extracted with phenol/chloroform and precipitated with absolute ethanol. The concentration of DNA was measured with a spectrophotometer, and $5 \mu \mathrm{g}$ DNA was fractionated by electrophoresis on a $1.8 \%$ agarose gel containing ethidium bromide. For staining of apoptotic bodies by Hoechst 33258, T47D cells were cultured in RPMI-1640 complete medium on a chamber slide $\left(1 \times 10^{4}\right.$ cells $\left./ \mathrm{ml}\right)$. After incubation, the culture medium was removed, and the cells were fixed by $4 \%$ formaldehyde for $20 \mathrm{~min}$. The fixing solution was then removed, and cells were washed three times. Cells were stained by Hoechst 33258 stain solution $(0.5 \mu \mathrm{g} / \mathrm{ml}$ in PBS) at room temperature for $30 \mathrm{~min}$. After staining, the solution was removed, the cells were washed three times with PBS, and one drop of mounting solution was added before application of a cover slip. Apoptotic cells exhibited blue, peripherally clumped or fragmented chromatin by fluorescence microscopy.

Apoptosis analysis by flow cytometry. Fluorescein-conjugated Annexin V (Annexin V-FITC) was used to quantitatively determine the percentage of cells undergoing apoptosis. Treated cells were washed twice with cold PBS and then resuspended in binding buffer at a concentration of $1 \times 10^{6}$ cells $/ \mathrm{ml}$. Five microliters of Annexin V-FITC and $10 \mu \mathrm{l}$ of propidium iodide were added to suspended cells. After incubation for $15 \mathrm{~min}$ at room temperature in the dark, the percentage of apoptotic cells was analyzed by flow cytometry (BectonDickinson FACScan, San Jose, CA).

Western blot analysis. Cells were lysed in whole lysis buffer (50 mM Tris-HCl, pH 7.5, $5 \mathrm{mM}$ EDTA, $150 \mathrm{mM} \mathrm{NaCl}$, and $1 \%$ Triton $\mathrm{X}-100)$ containing protease and phosphatase inhibitors ( $1 \mathrm{mM}$ PMSF, $2 \mu \mathrm{g} / \mathrm{ml}$ leupeptin, $4 \mu \mathrm{g} / \mathrm{ml}$ aprotinin, and $1 \mu \mathrm{g} / \mathrm{ml}$ pepstatin), and protein concentrations were determined using the Coomassie protein assay (Bradford). An equivalent amount of protein extract from each sample was electrophoresed by 8-12\% SDS-PAGE and transferred to nitrocellulose. Membranes were blocked for $1 \mathrm{~h}$ with $5 \%$ non-fat milk in T-TBS buffer (20 mM Tris- $\mathrm{HCl} \mathrm{pH} 7.6$, $137 \mathrm{mM} \mathrm{NaCl}, 0.1 \mathrm{X}$ Tween-20) and incubated overnight at $4^{\circ} \mathrm{C}$ with primary antibodies. Membranes were then washed three times in T-TBS and incubated with the corresponding secondary antibody, anti-mouse or -rabbit IgG HRP-conjugate (1:1000 dilution), in T-TBS with $5 \%$ non-fat milk for $1 \mathrm{~h}$ under agitation at room temperature. After washing three times in T-TBS, the membranes were developed by using the enhanced chemiluminescence (ECL) PLUS kit.

Oligonucleotide labeling and electrophoretic mobility shift assay (EMSA). The GAS1 probe consisted of a synthetic double-stranded oligonucleotide corresponding to the sequence
5'-CGTGGAGTTCTTGGAAATGCGCC-3'. The doublestranded DNA probe was end-labeled using $\mathrm{T}_{4}$ polynucleotide kinase and $\left[\gamma^{-32} \mathrm{P}\right]$ ATP. EMSAs were performed as described previously (8).

RNA interference. The siRNA constructs for STAT5b siRNA (pKD-STAT5b-v1) and negative control (pKD-NegCon-v1) were purchased from Upstate (Lake Placid, NY) (9). The siRNA target sequence is 21 nucleotides in length and was designed using a highly advanced search algorithm. The sequence contains perfect complementarity to the STAT5b gene target but contains minimal or no homology to other sequences within the genome. The siRNA target sequence was utilized to design the DNA oligonucleotides that were cloned into the pKD vector (Upstate). MCF-7 cells into 35-mm culture dishes were transfected with STAT5b siRNA (pKDSTAT5b-v1, $1 \mu \mathrm{g}$ ) or negative control (pKD-Negcon-v1, $1 \mu \mathrm{g}$ ) using the FuGene6 (Roche Applied Science) according to the manufacturer's recommendation.

Caspase activity assay. T47D cells under hypoxic conditions were treated with various concentrations of momilactone B for $24 \mathrm{~h}$. The cells were harvested and washed twice with PBS buffer. Caspase activity was measured by the FLICA (Fluorochrome Inhibitor of Caspases) apoptosis detection kit according to the procedure described by the manufacturer. Briefly, cells were labeled with the green fluorescent-labeled inhibitor FAM-VAD-FMK for $1 \mathrm{~h}$, washed, and analyzed. Caspase activity was detected using a BD FACScan flow cytometer.

\section{Results}

Cytotoxicity of momilactone B in human breast cancer cells. To determine the effect of momilactone $\mathrm{B}$ on cell survival, a human breast cancer cell line (T47D) was exposed to various concentrations of momilactone B $(25,50$, or $100 \mu \mathrm{M})$ for $24 \mathrm{~h}$ under hypoxic conditions. The number of momilactone Btreated cells in the logarithmic phase of growth was compared with that of control cells (hypoxia-treated cells). Cell growth was inhibited by $\sim 35 \%$ with $25 \mu \mathrm{M}$ momilactone $\mathrm{B}$ and by $\sim 50 \%$ with $50 \mu \mathrm{M}$ momilactone B (Fig. 2A). As compared with hypoxia or normoxia plus $50 \mu \mathrm{M}$ momilactone $\mathrm{B}$, hypoxia plus $50 \mu \mathrm{M}$ momilactone B-treated cells resulted in a marked decrease in cell number after $12 \mathrm{~h}$ (Fig. 2B). On the other hand, normoxia plus $50 \mu \mathrm{M}$ momilactone B-treated cells did not change. Thus, momilactone B treatment substantially decreased the viability of T47D cells in a dose- and timedependent manner.

Momilactone B promotes hypoxia-induced apoptosis in human breast cancer cells. Human breast cancer cell death under hypoxic conditions was evaluated by several techniques to determine whether this death was due to apoptosis. Likewise, to determine if momilactone B-induced cytotoxicity is mediated through apoptosis, several assays were performed. DNA fragmentation analysis of hypoxia-plus momilactone B-treated T47D cells showed the laddering pattern characteristic of apoptosis (Fig. 3A). These results were confirmed by the observation of apoptotic bodies in hypoxia-treated 
A

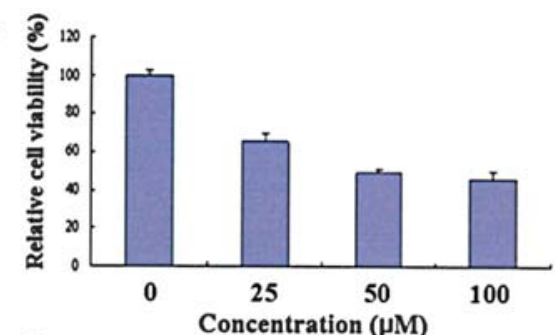

B

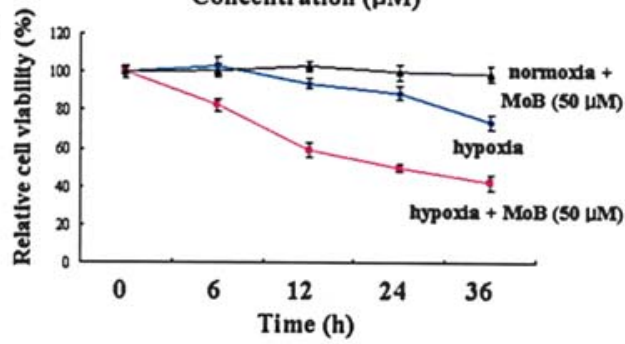

Figure 2. Effect of momilactone B on viability of T47D cells under hypoxic conditions. (A) Effect of momilactone B concentration on the relative number of T47D cells. Cells were cultured in 96-well dishes for $24 \mathrm{~h}$ and then treated with various concentrations of momilactone B for $24 \mathrm{~h}$. (B) Time course effects of momilactone $\mathrm{B}$ on the growth of T47D cells. Cells were cultured and exposed to $50 \mu \mathrm{M}$ momilactone $\mathrm{B}$ under normoxic or hypoxic condition for the indicated times. MoB, momilactone B. The error bars represent the standard deviation from three experiments.
T47D cells using Hoechst stain. Apoptotic cells exhibited blue, peripherally clumped or fragmented chromatin, as indicated by arrows in Fig. 3B. Apoptotic bodies were observed in T47D cells treated with $50 \mu \mathrm{M}$ momilactone $\mathrm{B}$ under hypoxic conditions. When T47D cells were treated with hypoxia for $24 \mathrm{~h}$, apoptosis was induced. We next investigated whether momilactone B promotes this hypoxia-induced apoptosis. After hypoxia treatment, the percentage of apoptotic cells increased to $15 \%$ by Annexin-PI staining, and this percentage was markedly increased to $34 \%$ when cells were treated with $50 \mu \mathrm{M}$ momilactone B (Fig. 3C). These results indicate that momilactone $\mathrm{B}$ accelerates hypoxia-induced apoptosis in human breast cancer cells.

Momilactone B inhibits the expression of hypoxia-related proteins in human breast cancer cells. In our previous studies, we found that hypoxia activates the cyclin D1 promoter via the Jak2/STAT5b pathway in breast cancer cells. To determine the effect of momilactone B on the Jak2/STAT5b pathway, the levels of various proteins regulated by hypoxia in human breast cancer cells were examined. MCF-7 cells were treated with $0,25,50$, and $100 \mu \mathrm{M}$ momilactone $\mathrm{B}$ under hypoxic conditions $\left(2 \% \mathrm{O}_{2}\right)$ for $24 \mathrm{~h}$. As shown in
A

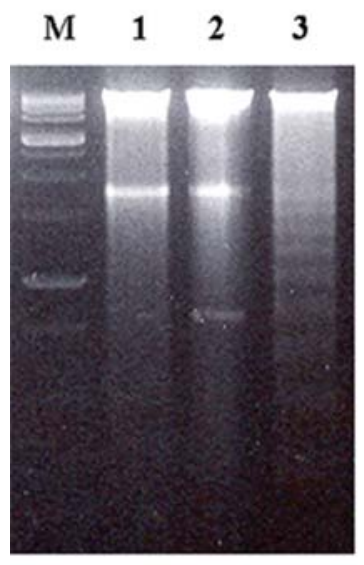

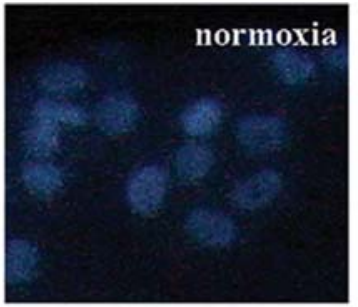

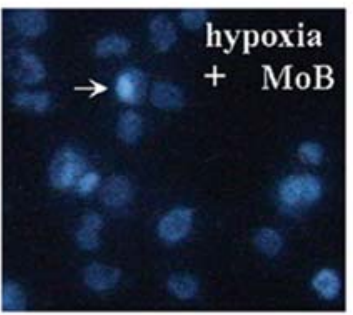

Hoechst

33258
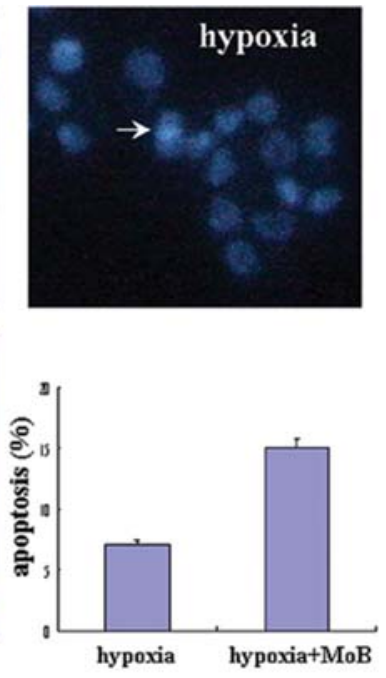

C
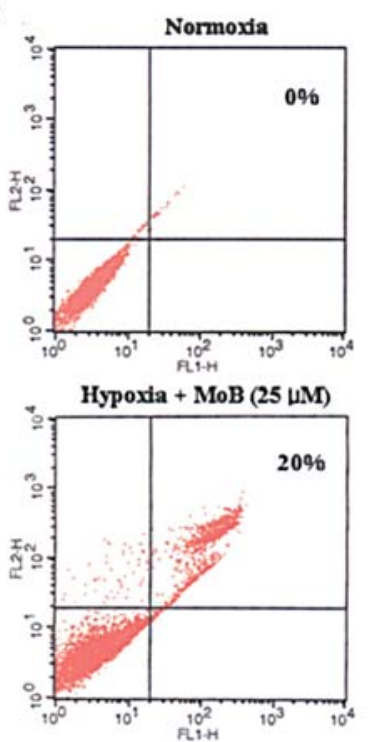
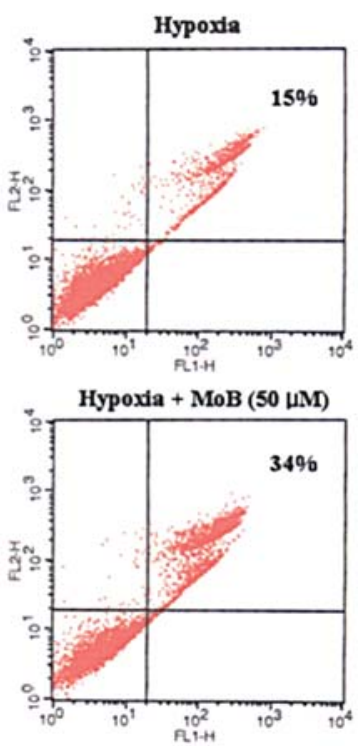

Figure 3. Hypoxia induces apoptosis, and momilactone B promotes hypoxiainduced apoptosis in T47D cells. (A) DNA was isolated, and ladder formation was examined by $1.8 \%$ agarose gel electrophoresis. Lane M, DNA ladder; lane 1 , normoxia; lane 2, hypoxia; lane 3 , hypoxia plus momilactone B. (B) T47D cells were treated with normoxia, hypoxia, or hypoxia plus momilactone B $(50 \mu \mathrm{M})$ before Hoechst staining and analysis of nuclei. Apoptotic cells exhibited blue, peripherally clumped or fragmented chromatin, as indicated by the arrows. MoB, momilactone B. Data are representative of three independent experiments. The error bars represent the standard deviation from three experiments. (C) T47D cells were treated with normoxia (control), hypoxia, or hypoxia plus $50 \mu \mathrm{M}$ momilactone $\mathrm{B}$. Treated cells were analyzed by flow cytometry using Annexin V-FITC as described in Materials and methods, and the percentage of cells in apoptosis was determined. The $\mathrm{x}$-axis represents the fluorescence intensity of Annexin V-FITC, and the $\mathrm{y}$-axis represents the intensity of propidium iodide. $\mathrm{MoB}$, momilactone $\mathrm{B}$. Data are representative of three independent experiments. 
A

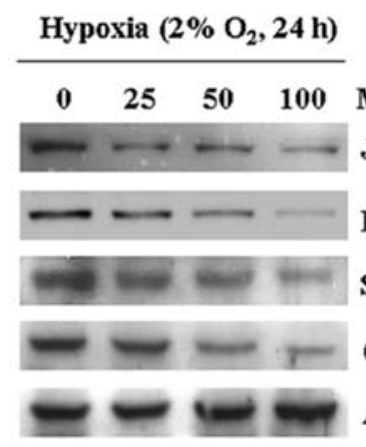

C

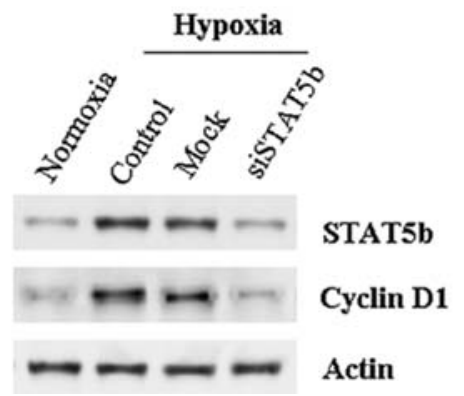

B
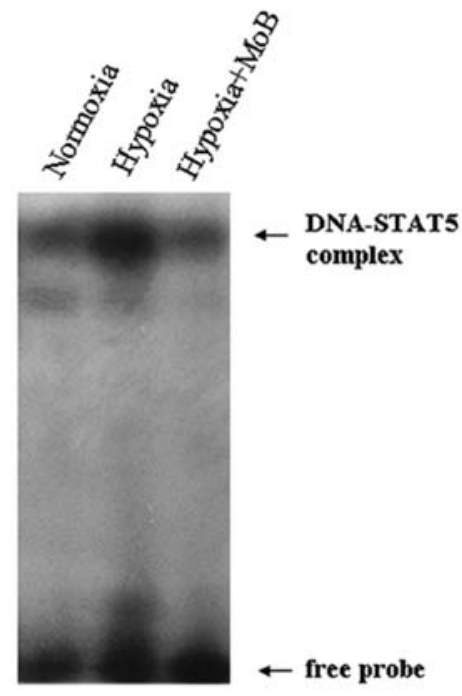

D

Hypoxia

- $\quad+$ siSTATSb

$-++\operatorname{MoB}(50 \mu \mathrm{M})$

STAT5b

Cyclin D1

Actin

Figure 4. Effects of momilactone B on Jak2/STAT5b pathway-related proteins activated by hypoxia. (A) Momilactone B inhibits expression of the Jak2/STAT5b pathway-related proteins regulated by hypoxia. MCF-7 cells were treated with momilactone $\mathrm{B}$ concentration $(0,25,50$, and $100 \mu \mathrm{M})$ under hypoxic condition $\left(2 \% \mathrm{O}_{2}\right)$ for $24 \mathrm{~h}$. Protein extracts $(20 \mu \mathrm{g})$ were separated by $12 \%$ SDS-PAGE, and Western blot analyses were performed as described in Materials and methods. B-actin was used as a control for protein loading. (B) Momilactone B suppresses the hypoxia-induced binding of STAT5 to the cyclin D1-GAS1 site. MCF-7 cells were treated with normoxia (control), hypoxia, or hypoxia plus $50 \mu \mathrm{M}$ momilactone B, and STAT5 DNA binding was detected by EMSA. Nuclear extracts were incubated with $\left[{ }^{32} \mathrm{P}\right]$-labeled probe specific for the GAS1 site. The resulting complexes were electrophoresed on a $6 \%$ non-denaturing gel. MoB, momilactone B. Shown is a representative gel from three independent experiments. (C) MCF-7 cells were treated with mock (pKD-NegCon) or siSTAT5b (pKD-siSTAT5b) under hypoxic conditions. Cells were harvested after $24 \mathrm{~h}$ for assay of STAT5b, cyclin D1 and B-actin by immunoblotting. (D) MCF-7 cells were treated with $50 \mu \mathrm{M}$ momilactone B or $50 \mu \mathrm{M}$ momilactone B with transfected siSTAT5b (pKD-siSTAT5b) under hypoxic conditions. Cells were harvested after $24 \mathrm{~h}$ for assay of STAT5b, cyclin D1 and B-actin by immunoblotting.

Fig. 4A, the protein levels of Jak2, phospho-STAT5, STAT5b, and cyclin D1, which are increased by hypoxia, were dosedependently down-regulated by momilactone B. These results indicate that the growth inhibitor momilactone $B$ regulates the cyclin D1 promoter via the Jak2/STAT5b pathway in hypoxic human breast cancer cells.

Momilactone B suppresses the hypoxia-induced binding of STAT5 to the cyclin D1-GAS1 site. Activated STATs form dimers, translocate to the nucleus, bind to specific response elements in the promoters of target genes, and transcriptionally activate these genes. Under hypoxic conditions, STAT5b recognizes the GAS sequence in the promoter of cyclin D1. Hypoxia increases STAT5b DNA-binding activity in human breast cancer cells (2). To test the hypothesis that momilactone B inhibits STAT5b, we examined the binding of STAT5b to the GAS1 promoter under hypoxic conditions. As shown in Fig. 4B, MCF-7 cells were treated with normoxia (control), hypoxia, or hypoxia plus $50 \mu \mathrm{M}$ momilactone $\mathrm{B}$. The results show that momilactone B suppressed hypoxiainduced STAT5 DNA-binding activity in human breast cancer cells.

The increase of cyclin D1 expression by hypoxia and reduction of cyclin D1 expression by STAT5b knock-down. STAT5b protein levels were monitored by Western blotting from negative control and STAT5b knock-down cells $24 \mathrm{~h}$ following siRNA transfection. As a control, $\beta$-actin expression was shown to be unaffected following STAT5b knock-down at the protein level. Treatment of MCF-7 cells with siRNASTAT5b resulted in efficient and specific inhibition of STAT5b transcripts. And, the siRNA-STAT5b reduced high significantly the cyclin D1 expression in MCF-7 cells (Fig. 4C). Thus, cyclin D1 is a target gene of hypoxia signal transduction and the regulation in cyclin D1 protein level is likely to be the result of hypoxia activation of STAT5b. In addition, the expression of STAT5b and cyclin D1 by treatment of $50 \mu \mathrm{M}$ momilactone B with siRNA-STAT5b were more reduced than by treatment of only $50 \mu \mathrm{M}$ momilactone $\mathrm{B}$ without siRNA-STAT5b under hypoxic condition of MCF-7 cells (Fig. 4D).

Momilactone B affects the expression of apoptosis-related proteins in human breast cancer cells under hypoxic conditions. Immunoblot analyses were performed to determine the levels of different proteins controlling cell proliferation and/or apoptosis in MCF-7 and T47D cells (Fig. 5), focusing on the expression of bcl-2 and bax proteins. Bcl-2 and bax are homologous proteins that have opposing effects on cell life and death, with bcl-2 serving to prolong cell survival and 
A

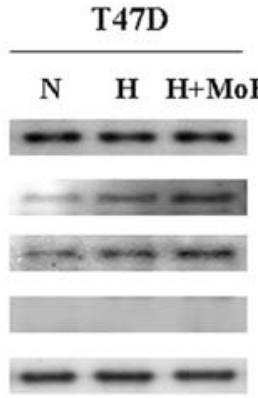

B

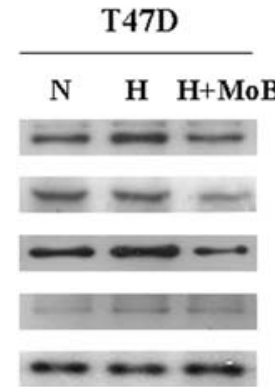

MCF-7

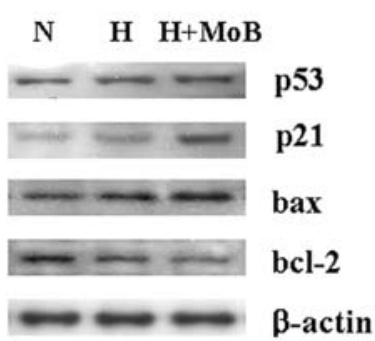

\section{MCF-7}
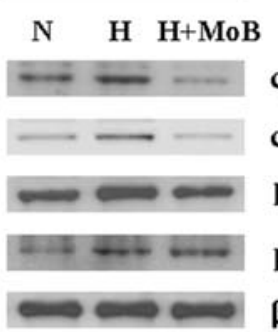

cyclin D1

cdk4 ppRb

$\mathrm{pRb}$

$\beta$-actin

Figure 5. Momilactone B affects the expression of apoptosis-related proteins in MCF-7 and T47D cells under hypoxic conditions. Hypoxia treated cells were treated with momilactone $\mathrm{B}(50 \mu \mathrm{M})$ for different periods of time. The protein extracts $(20 \mu \mathrm{g})$ were separated by $12 \%$ SDS-PAGE, and Western blot analyses were performed as described in Materials and methods. B-actin was used as a control for protein loading. N, normoxia; H, hypoxia; MoB, momi-lactone B. Shown are representative blots from three independent experiments.

bax acting as an accelerator of apoptosis. Bcl-2 expression was slightly down-regulated by the addition of $50 \mu \mathrm{M}$ momilactone $\mathrm{B}$ when cells were exposed to hypoxic conditions for $24 \mathrm{~h}$ in only MCF-7 cells. In contrast, the expression of bax was up-regulated by momilactone B treatment (Fig. 5A). Phosphorylation of $\mathrm{pRb}$ is required for cell cycle progression, and changes in the phosphorylation status of $\mathrm{pRb}$ are observed with apoptosis. Therefore, the phosphorylation status of $\mathrm{pRb}$ in T47D and MCF-7 cells was examined following treatment with $50 \mu \mathrm{M}$ momilactone $\mathrm{B}$ under hypoxic conditions. T47D cells showed a dramatic loss of hyperphosphorylated forms of $\mathrm{pRb}$ with momilactone $\mathrm{B}$ treatment, whereas no detectable change in $\mathrm{pRb}$ phosphorylation was observed in MCF-7 cells (Fig. 5B). The loss of the hyperphosphorylated forms of $\mathrm{pRb}$ coincided with the induction of apoptosis.

Momilactone B induces caspase-dependent cell death of human breast cancer cells under hypoxic conditions. As shown in Fig. 3, momilactone B induced apoptosis under hypoxic conditions. To determine whether caspases are involved in this hypoxia-induced apoptosis, caspase activity in human breast cancer cells was analyzed using a potent caspase inhibitor, FAM-VAD-FMK. Compared with control (normoxia) cells, caspase activity increased by $16 \%$ in hypoxia-treated cells, and this percentage dose-dependently increased to $33 \%$ when cells were treated with $50 \mu \mathrm{M}$ momilactone B under hypoxic conditions (Fig. 6A). Hypoxiainduced apoptosis was evaluated further by measurement
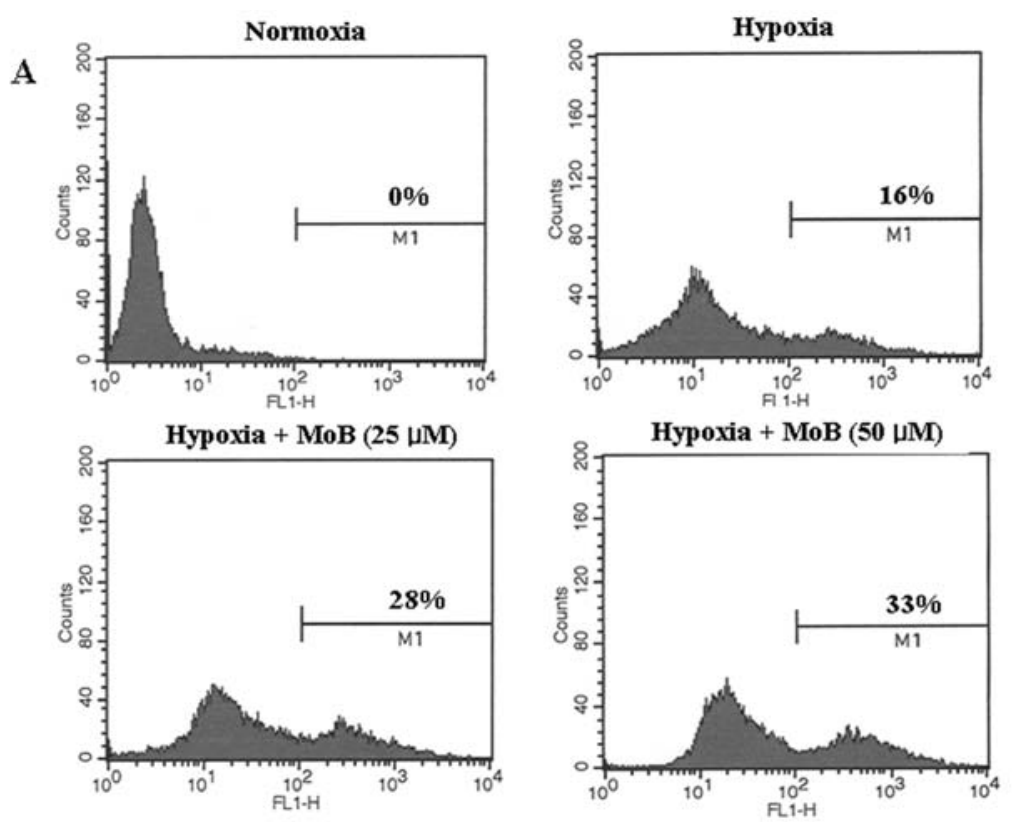

B

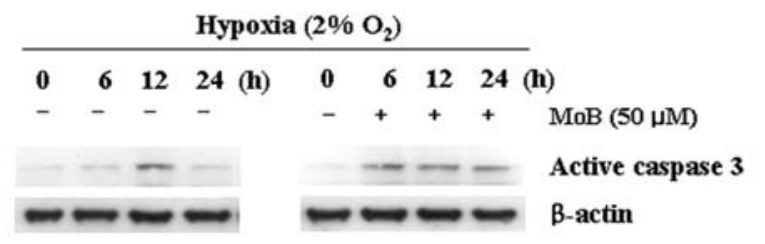

Figure 6. Momilactone B induces caspase-dependent cell death of breast cancer cells under hypoxic conditions. (A) T47D cells were treated with normoxia (control), hypoxia, or hypoxia plus $50 \mu \mathrm{M}$ momilactone B. Treated cells were labeled with the green fluorescent-labeled inhibitor FAM-VAD-FMK for $1 \mathrm{~h}$, washed, and analyzed. Caspase activity was detected using a BD FACScan flow cytometer. (B) Whole cell lysates were prepared from MCF-7 and T47D cells. A total of $20 \mu \mathrm{g}$ cell lysate was separated on $12 \%$ SDS-PAGE, transferred to nitrocellulose, and probed with cleaved caspase-3 antibody. Then, the blot was stripped and reprobed with the anti-actin antibody. Caspase-3 was not detected in MCF-7 cells (not shown). Data are representative of three independent experiments. 
of the cysteine protease caspase-3, which is essential for apoptotic death in mammalian cells. It was established previously that MCF-7 cells do not express a functional caspase-3. Consistent with those results, we did not detect caspase-3 expression in MCF-7 cells, but a 17-kDa band likely corresponding to active caspase- 3 was detected in the T47D cell line. The caspase-3-like activity was markedly increased $12 \mathrm{~h}$ after hypoxia treatment (Fig. 6B). Treatment with $50 \mu \mathrm{M}$ momilactone $\mathrm{B}$ under hypoxic conditions for $6 \mathrm{~h}$ caused an even greater increase in caspase-3-like activity. These results indicate that apoptosis induced by momilactone $\mathrm{B}$ under hypoxic conditions is dependent upon caspase activation.

\section{Discussion}

The present study demonstrates that momilactone B accelerates hypoxia-induced apoptosis in human breast cancer cells through STAT5b. When STAT5b was inhibited by momilactone $\mathrm{B}$ in human breast cancer cells under hypoxic conditions, the levels of cyclin D1, CDK4, phospho-pRb, caspase-3, and bcl-2 (only in MCF-7 cells) were markedly reduced, and the levels of bax and p21 were increased. Momilactone B suppressed STAT5 DNA-binding activity induced by hypoxia in human breast cancer cells. siRNASTAT5b assay showed the ability to knock-down at $>70 \%$ of the cyclin D1 expression by immunoblotting. Thus, the inhibition of STAT5 DNA binding activity is likely to be through STAT5b inhibition that momilactone B induces apoptosis. These results support the feasibility of utilizing momilactone B to induce apoptosis in certain STAT5-activated human breast cancers.

Several constitutively activated STAT proteins have been observed to contribute directly to oncogenesis by stimulating cell proliferation and preventing apoptosis in various cancers (24). STAT5 participates in oncogenesis by up-regulating genes encoding apoptosis inhibitors and cell cycle regulators, including bcl-xL, cyclin D1, and p21 $(13,25)$. In addition, cyclin D1 has been shown to be regulated by STAT5b (26). Moreover, we have shown previously that STAT5b may mediate transcriptional activation of cyclin D1 after hypoxic stimulation in human breast cancer cells (2) pRb phosphorylation is a critical step in the G1-to-S phase transition. Phosphorylation of $\mathrm{pRb}$ is controlled primarily by complexes of D cyclins associated with cdk4/6 and later by cyclin E associated with cdk2 $(27,28)$. The present study shows that momilactone B's inhibitory effect on cell cycle progression under hypoxic conditions is due to rapid down-regulation of cyclin D1 and cdk4 expression, which in turn decreases pRb hyperphosphorylation. Treatment of human breast cancer cells with momilactone B under hypoxic conditions led to reduced $\mathrm{pRb}$ phosphorylation on serine 795 , a site that is known to be phosphorylated by the cyclin D1/cdk4 complex.

Cell death due to hypoxia is a major concern in various clinical entities such as ischemic diseases. Until recently, cell death by hypoxia was generally thought to be manifested as necrosis (29). In contrast, recent biochemical observations have suggested the possibility of hypoxia-induced apoptosis. Hypoxia treatment induces endothelial cell death through the induction of apoptosis, consistent with previous findings $(30,31)$. This study has shown that hypoxia induces apoptosis in human breast cancer cells, and the apoptosis is promoted by momilactone $\mathrm{B}$.

Rice hulls, from which momilactone B is extracted, have recently been reported to contain antioxidant substances that protect the rice seed from oxidative stress (17). As a potential chemopreventive or therapeutic agent against breast cancer, momilactone $\mathrm{B}$ has several advantages. The rice hull comprises $20 \%$ of the rice grain kernel and, similar to other plant biomass, contains a high percentage of organic substances. It is therefore recognized as a potential source of energy and organic chemicals (21).

Momilactone B in combination with hypoxia stimulation showed a cytotoxic effect in cultured human breast cancer cells, and flow cytometry analysis using Annexin V-PI staining implicated apoptosis as the cell death mechanism. In addition, observations of DNA laddering and apoptotic bodies confirmed that momilactone $\mathrm{B}$ induces apoptosis under hypoxic conditions. The activation of caspases is a key regulator of apoptosis. Tumor cell apoptosis was associated with caspase protein expression and caspase- 3 activity. The pro-caspase protein was in its inactive form when the cell was in the resting state, and the protein expression was decreasing to convert to the active form of caspase- 3 in the process of apoptosis $(32,33)$. Caspase- 3 activation is known to occur under hypoxic conditions in various cells, including cardiomyocytes (34). In the present study, caspase activity and active caspase- 3 protein expression were increased by momilactone B treatment under hypoxic conditions, demonstrating that momilactone B caused cell death through caspase-3-dependent apoptosis. Moreover, we explored factors upstream of the caspase pathway. During apoptosis, the intra-cytosolic balance of members of the antiapoptotic bcl-2 family of proteins is critical for maintaining the integrity of the mitochondrial membrane $(35,36)$. Bcl-2 heterodimerizes in vivo with its conserved, proapoptotic homolog bax, which is also known to prevent bax oligomerization and its insertion into the mitochondrial membrane $(37,38)$. Immunoblot analyses demonstrated that exposure of hypoxic cells to momilactone B increased the level of bax and reduced the level of bcl-2 (only in MCF-7 cells).

The cyclin-dependent kinase inhibitor p21 was reported to be a STAT5-regulated gene in the p53-deficient CMK human megakaryoblastic leukemia cell line. p21 is induced by both p53-dependent and p53-independent mechanisms following stress, and induction of p21 may cause cell cycle arrest (39). Our data showed that the inhibition of STAT5b by momilactone $B$ resulted in marked expression of $\mathrm{p} 21$ in T47D and MCF-7 cells. However, the level of p53 protein did not change (expressed as mutant form in T47D and as wild-type in MCF-7 cells). Thus, momilactone B-induced apoptosis under hypoxic conditions occurred independently of the p53 protein level in human breast cancer cells.

This study showed that hypoxia-induced increases in STAT5b and cyclin D1 were down-regulated by momilactone B. In human breast cancer cells under hypoxic conditions, growth inhibitory and apoptotic processes, activation of caspase- 3 activity, apoptotic body formation, and increased apoptosis were characteristics of the cell death effect induced by momilactone B. The apoptosis pathway of human breast cancer cells induced by momilactone B under 
hypoxic conditions was mediated by STAT5b and caspase- 3 but not by $\mathrm{p} 53$. Thus, momilactone B may be potentially effective chemopreventive or therapeutic agent for breast cancer. However, further in vivo studies are needed to establish the mechanism of momilactone B as an anti-breast cancer agent.

\section{Acknowledgments}

This work was supported by Konkuk University in 2004.

\section{References}

1. Pouyssegur J, Dayan F and Mazure NM: Hypoxia signaling in cancer and approaches to enforce tumor regression. Nature 441: 437-443, 2006.

2. Joung YH, Lim EJ, Lee MY, Park JH, Ye SK, Park EU, Kim SY, Zhang Z, Lee KJ, Park DK, Park TK, Moon WK and Yang YM: Hypoxia activates the cyclin D1 promoter via the Jak2/STAT5b pathway in breast cancer cells. Exp Mol Med 37: 353-364, 2005.

3. Schmaltz C, Hardenbergh PH, Wells A and Fisher DE: Regulation of proliferation-survival decisions during tumor cell hypoxia. Mol Cell Biol 18: 2845-2854, 1998

4. Graeber TG, Osmanian C, Jacks T, Housman DE, Koch CJ, Lowe SW and Giaccia AJ: Hypoxia-mediated selection of cells with diminished apoptotic potential in solid tumours. Nature 379: 88-91, 1996.

5. Vaupel P, Kelleher DK and Hockel M: Oxygen status of malignant tumors: pathogenesis of hypoxia and significance for tumor therapy. Semin Oncol 28: 29-35, 2001.

6. Pettersen EO, Juul NO and Ronning OW: Regulation of protein metabolism of human cells during and after acute hypoxia. Cancer Res 46: 4346-4351, 1986.

7. Shih SC and Claffey KP: Hypoxia-mediated regulation of gene expression in mammalian cells. Int J Exp Pathol 79: 347-357, 1998.

8. Joung YH, Park JH, Park TK, Lee CS, Kim OH, Ye SK, Yang UM, Lee KJ and Yang YM: Hypoxia activates signal transducers and activators of transcription 5 (STAT5) and increases its binding activity to the GAS element in mammary epithelial cells. Exp Mol Med 35: 350-357, 2003.

9. Joung YH, Lee MY, Lim EJ, Kim MS, Hwang TS, Kim SY, Kim SY, Ye SK, Lee JD, Park TK, Woo YS, Chung IM and Yang YM: Hypoxia activates the IGF-1 expression through STAT5b in human HepG2 cells. Biochem Biophys Res Commun 358: 733-738, 2007.

10. Lee MY, Joung YH, Lim EJ, Park JH, Ye SK, Park TK, Zhang Z, Park DK, Lee KJ and Yang YM: Phosphorylation and activation of STAT proteins by hypoxia in breast cancer cells. Breast 15 : 187-195, 2006.

11. Chin YE, Kitagawa M, Kuida K, Flavell RA and Fu XY: Activation of the STAT signaling pathway can cause expression of caspase 1 and apoptosis. Mol Cell Biol 17: 5328-5337, 1997.

12. Dudley AC, Thomas D, Best J and Jenkins A: A VEGF/JAK2/ STAT5 axis may partially mediate endothelial cell tolerance to hypoxia. Biochem J 390: 427-436, 2005.

13. Yamashita H, Nishio M, Fujii Y and Iwase H: Dominantnegative Stat5 inhibits growth and induces apoptosis in T47Dderived tumors in nude mice. Cancer Sci 95: 662-665, 2004.

14. Mo H and Elson CE: Apoptosis and cell-cycle arrest in human and murine tumor cells are initiated by isoprenoids. J Nutr 129: 804-813, 1999.

15. Behrens P, Brinkmann U and Wellmann A: CSE1L/CAS: its role in proliferation and apoptosis. Apoptosis 8: 39-44, 2003.

16. Sun J and Liu RH: Cranberry phytochemical extracts induce cell cycle arrest and apoptosis in human MCF-7 breast cancer cells. Cancer Lett 241: 124-134, 2006.

17. Kim SJ, Park HR, Park EJ and Lee SC: Cytotoxic and antitumor activity of Momilactone B from rice hulls. J Agric Food Chem 55: 1702-1706, 2007.
18. Tseng TH, Tsheng YM and Lee YJ: Cytotoxicity effects of diand tri-hydroxybenzaldehydes as a chemopreventive potential agent on tumor cells. Toxicology 161: 179-187, 2001.

19. Semenza GL: Angiogenesis in ischemic and neoplastic disorders. Annu Rev Med 54: 17-28, 2003.

20. More A, Cruz JM, Franco D, Domiguez JM, Sineiro J, Dominguez H, Nunez MJ and Parajo JC: Natural antioxidants from residual sources. Food Chem 72: 145-171, 2001.

21. Kalapathy U, Proctor A and Shultz J: Silicate thermal insulation material from rice hull ash. Ind Eng Chem Res 42: 46-49, 2003.

22. Hisashi KN and Takeshi I: Rice seedling release momilactone B into the environment. Phytochemistry 63: 551-554, 2003.

23. Chung IM, Kim JT and Kim SH: Evaluation of allelopathic potential and quantification of Momilactone A,B from rice hull extracts and assessment of inhibitory bioactivity on paddy field weeds. J Agric Food Chem 54: 2527-2536, 2006.

24. Bromberg J: Stat proteins and oncogenesis. J Clin Invest 109: 1139-1142, 2002

25. Battle TE and Frank DA: The role of STATs in apoptosis. Curr Mol Med 2: 381-392, 2002.

26. Buettner R, Mora LB and Jove R: Activated STAT signaling in human tumors provides novel molecular targets for therapeutic intervention. Clin Cancer Res 8: 945-954, 2002.

27. Sherr CJ and Roberts JM: CDK inhibitors: positive and negative regulators of G1-phase progression. Genes Dev 13: 1501-1512, 1999.

28. Koziczak M, Holbro T and Hynes NE: Blocking of FGFR signaling inhibits breast cancer cell proliferation through downregulation of D-type cyclins. Oncogene 23: 3501-3508, 2004.

29. Yamamoto K, Morishita R, Hayashi S, Matsushita H, Nakagami H, Moriguchi A, Matsumoto K, Nakmura T, Kaneda Y and Ogihara T: Contribution of bcl-2, but not bcl-xL and bax, to antiapoptotic actions of hepatocyte growth factor in hypoxia-conditioned human endothelial cells. Hypertension 37: 1341-1348, 2001.

30. Harrison-Shostak DC, Lemasters JJ, Edgell CJ and Herman B: Role of ICE-like pretease in endothelial cell hypoxic and reperfusion injury. Biochem Biophys Res Commun 231: 844-847, 1997.

31. Muschel RJ., Bernhard EJ, Garza L, McKenna WG and Koch CJ: Induction of apoptosis at different oxygen tensions: evidence that oxygen radicals do not mediate apoptotic signaling. Cancer Res 55: 995-998, 1995.

32. Thornberry $\mathrm{N}$ and Lazebnik Y: Caspases: enemies within. Science 281: 1312-1316, 1998.

33. Yang YP, Kuo HS, Tsai HD, Peng YC and Lin YL: The p53dependent apoptotic pathway of breast cancer cells (BC-M1) induced by the bis-type bioreductive compound aziridinylnaphthoquinone. Breast Cancer Res 7: R19-R27, 2005.

34. Adachi S, Ito H, Tamamori-Adachi M, Ono Y, Nozato T, Abe S, Ikeda MA, Marumo F and Hiroe M: Cyclin A/cdk2 activation is involved in hypoxia-induced apoptosis in cardiomyocytes. Circ Res 88: 408-414, 2001.

35. Shrivastava A, Tiwari M, Sinha RA, Kumar A, Balapure AK., Bajpai VK, Sharma R, Mitra K, Tandon A and Godbole MM: Molecular iodine induces caspase-independent apoptosis in human breast carcinoma cells involving mitochondria-mediated pathway. J Biol Chem 281: 19762-19771, 2006.

36. Zhang JH, Zhang Y and Herman B: Caspase, apoptosis and aging. Ageing Res Rev 2: 357-366, 2003.

37. Oltvai ZN, Milliman S and Korsmeyer SJ: Bcl-2 heterodimerizes in vivo with a conserved homolog, Bax, that accelerates programmed cell death. Cell 74: 609-619, 1993.

38. Antonsson B, Montessuit S, Sanchez B and Martinou JC: Bax is present as a high molecular weight oligomer/complex in the mitochondrial membrane of apoptotic cells. J Biol Chem 276: 11615-11623, 2001.

39. Matsumura I, Ishikawa J, Nakajima K, Oritani K, Tomiyama Y, Miyagawa J, Kato T, Miyazaki H, Matsuzawa Y and Kanakura Y: Thrombopoietin-induced differentiation of a human megakaryoblastic leukemia cell line, CMK, involves transcriptional activation of p21 (WAF1/Cip1) by STAT5. Mol Cell Biol 17: 2933-2943, 1997. 